\title{
Um Diálogo Entre o Filme "O menino e o mundo" e a Educação Ambiental Crítica na Formação de Professores
}

\author{
Dialogue Between the Film "Boy and the World" and Critical Environmental Education \\ in Teacher Training \\ Un diálogo entre la película "El niño y el mundo" y la Educación Ambiental Crítica en la \\ Formación de Profesores
}

\author{
Gustavo Henrique Alves Silva \\ Graduando, UFLA, Brasil \\ guxtavohenrique@outlook.com
Andressa Aparecida Castro Graduanda, UFLA,Brasil \\ andressaprcastro@gmail.com \\ Marina Battistetti Festozo \\ Professora Doutora, UFLA, Brasil \\ mbfesozo@hotmail.com
}




\section{RESUMO}

Este trabalho busca relatar uma atividade realizada no Estágio Supervisionado III do curso de Ciências Biológicas, da Universidade Federal de Lavras, MG a qual buscou estabeler um diálogo entre a educação ambiental crítica e o filme "O menino e o mundo", uma animação de Alê Abreu. Essa atividade teve o intuito de estabelecer um diálogo entre a educação ambiental crítica e o filme "O menino e o mundo" a partir das falas dos estudantes da disciplina de Estágio Supervisionado III do curso de Licenciatura em Ciências Biológicas da Universidade Federal de Lavras,MG. as análises do filme realizadas pelos alunos, foi utilizada a Metodologia Qualitativa, por meio da Categorização Temática. Utilizando as análises das categorias foi possível perceber que a maioria dos alunos compreenderam a Educação Ambiental Crítica de uma maneira ampla e não apenas em seu sentido biológico, o que evidencia a importância de aproveitar tais momentos de discussão coletiva do estágio para se apropriar de aspectos relevantes para formação inicial de professores críticos, reflexivos e transformadores.

PALAVRAS-CHAVE: Educação Ambiental. Formação inicial de professores. Estágio supervisionado.

\section{ABSTRACT}

This work begins with an activity carried out in the Supervised Stage III of the Biological Sciences course in Federal University of Lavras. It was made an analysis by the students about "Boy and the World", animated film by Alê Abreu. This activity aimed to complement and improve the training on Critical Environmental Education and to discuss the importance of using cinema in educational process. To discuss the film analysis o made by the students, a qualitative methodology was used, through thematic categorization. Using the categories analysis we perceive that most of the students were able to understand Critical Environmental Education in a broad way and not only in their biological sense. This evidences the importance of taking advantage of the stage's moments of collective discussion to appropriate aspects relevant for the initial formation of critical, reflexive and transformative teachers.

KEY WORDS: Environmental education. Initial teacher training. Supervised internship.

\section{RESUMEN}

Este trabajo se inicia en una actividad realizada en la Pasantía Supervisionado III del curso de ciencias biológicas de la Universidad Federal de Lavras, y pate del análisis realzado por los estudiantes de la película "El niño y el mundo", animación de Ale Abreu. Esa actividad tuvo la intención de complementar y enriquecer la formación sobre la Educación Ambiental Crítica y discutir la importancia de la utilización del cine en el proceso de enseñanza y aprendizaje. Para discutir sobre los análisis de la película realizada por los estudiantes, fue utilizada la metodología cualitativa, por medio de categorización temática. Utilizando los análisis de las categorías fue posible percibir que la mayoría de los alumnos pudieron comprender la Educación Ambienta Crítica de una manera amplia y no solamente en su sentido biológico, lo que evidencia la importancia de aprovechar tales momentos de discusión colectiva de la pasantía para apropiarse de aspectos relevantes para la formación inicial de profesores críticos, reflexivos y transformadores.

PALABRAS CLAVE: Educación Ambiental. Formación Inicial de Professores. Pasantía Supervisionado. 


\section{INTRODUÇÃO}

"O menino e o mundo" é uma animação de Alê Abreu e estreou comercialmente no Brasil em 2014. A história do filme é contada a partir da visão de uma criança, com desenhos simples e uma trilha sonora que dão um toque poético à narrativa, proporcionando a sensibilização dos espectadores. O filme retrata a situação contemporânea do Brasil, representada por meio de traços e cores que podem ser relacionados a acontecimentos passados que também determinam a atual conjuntura do país, que é caracteriza por: desigualdade social, exploração dos recursos naturais e do trabalho, exportação, desmatamento, a questão da humanização, desvalorização da agricultura familiar, influência da mídia, entre outros.

Diante disso, o filme traz diversas reflexões que partem de um contexto histórico e perpassam os âmbitos sociais, políticos e econômicos fazendo uma crítica ao sistema capitalista vigente ao retratar problemas decorrentes dele.

A obra também apresenta diversos fatores ambientais que estão envolvidos com questões políticas, sociais, econômicas e culturais. Fatores estes que dentro da perspectiva da Educação Ambiental Crítica, se fazem importantes de serem analisados de maneira crítica e coletiva, para que com isso se leve à emancipação dos sujeitos, e à sua transformação por meio da compreensão da realidade de maneira completa e não fragmentada (LOUREIRO, TOZONI-REIS, 2007).

O termo meio ambiente pode ser pensando através da relação do homem com o meio ambiente, o que difere cada conceito é a forma como o homem interpreta tal relação, que vai desde seu sentido naturalista, resumindo o ambiente apenas em seu sentido biológico a compreender o ambiente o ambiente sem sua abordagem com um viés critico, onde ele é influenciado e modificado por aspectos socais, políticos, econômicos, culturais, entre outros. Trein (2012) afirma que historicamente o homem constrói sua relação com a natureza de forma a explorar a natureza para seu próprio beneficio. Nesse sentido é necessário que este contexto seja discutido e repensado, para que isso ocorra é necessário compreender o ambiente em um sentido mais amplo, para que o homem possa se reconhecer como parte do meio além de compreendê-lo e transformá-lo, Essas ideias vão de acordo com as ideias de Paulo Freire (2005), que apresenta uma concepção dialética da educação, frisando a importância de ser levado em consideração todo o contexto social na prática pedagógica para a formação de cidadãos críticos, reflexivos e transformadores.

Em consonância com as ideias de Paulo Freire entende-se que a escolha de recursos metodológicos alternativos é de fundamental importância para a prática pedagógica do professor que visa a formação de sujeitos críticos. Assim, o cinema é um recurso que tem grande potencial para contribuir no processo de formação dos alunos, uma vez que segundo Cabrera (2006) ele trabalhará a sensibilização, criatividade, imaginação, capacidade de identificar realidades diferentes, dentre outras qualidades dos alunos.

Ainda neste sentido, o autor complementa dizendo que a linguagem cinematográfica, a partir de uma visão filosófica, permite definir três categorias presentes nos filmes. A primeira trata da potencialidade de apresentar a realidade da maneira que ela é, ao mesmo tempo racional e efetiva, a segunda categoria diz sobre a capacidade que o cinema tem de impactar o expectador, o sensibilizando e a última categoria que o autor traz é sobre a capacidade que o 
cinema tem de fazer com que as pessoas sejam capazes de compreender realidades distintas (CABRERA, 2006).

Portanto, a utilização de filmes na formação inicial de professores é importante para que os futuros educadores compreendam a importância de que ao se trabalhar com expressões cinematográficas, é importante ter clareza dos objetivos, como também um vasto conhecimento teórico/prático sobre o tema a ser abordado, para que assim a escolha do filme seja feita de forma crítica, com o intuito de promover um aprendizado mais eficaz.

Além disso, é importante que o professor em formação compreenda que, a partir de um filme, é possível discutir diversas questões relacionadas ao ambiente como um todo.

Vale ressaltar que o modelo educacional brasileiro passou por diversas concepções de ensino, antes de passar por tais reflexões, que variam desde a Escola Tradicional, a influência da "Escola Nova" nas décadas de 1950 e 1960, o Ensino Tecnicista na década de 1970 e a chegada da Pedagogia Histórico-Crítica nos anos 1980, até os dias atuais com a Pedagogia das Competências (PIMENTA, 2004).

Compreender este contexto histórico, do modelo educacional brasileiro, permite pensar, refletir e discutir como era realizada a prática docente nos anos anteriores e como estes acontecimentos ainda geram grande influência no sistema educacional em vigência.

Para a formação de um professor crítico reflexivo é necessário que estas questões sejam discutidas, para ele que reconheça sua formação e sua atuação na escola em sua totalidade, conhecendo o contexto que determina sua realidade.

Desse modo, é necessário que a formação inicial de professores seja repensada, uma vez que temos como forte tendência no atual modelo educacional brasileiro a Pedagogia das Competências, termo que ganhou força desde 1990 e busca a formação de indivíduos para atender o mercado de trabalho (HOLANDA; FRERES; GONÇALVES, 2009).

Nesta perspectiva, o estágio na formação inicial de professores permite conhecer um pouco da realidade da escola e refletir sobre os conteúdos e práticas adotadas por ela, buscando transformar as marcas históricas de uma participação passiva. Dessa forma, o estágio se preza como uma ferramenta pela busca de uma educação transformadora e critica.

Assim, este trabalho busca estabelecer um diálogo entre a educação ambiental crítica e o filme "O menino e o mundo" a partir das falas dos estudantes da disciplina de Estágio Supervisionado III do curso de Licenciatura em Ciências Biológicas da Universidade Federal de Lavras,MG.

\section{DESENVOLVIMENTO}

Considerando estas preocupações, este trabalho parte de uma atividade realizada no segundo semestre de 2017 por meio do Estágio Supervisionado III, disciplina ofertada no curso de Ciências Biológicas da Universidade Federal de Lavras, Minas Gerais. O presente estágio teve o intuito de trabalhar com os futuros docentes em formação a Educação Ambiental Crítica.

O foco deste estágio é o estudo da Educação Ambiental a partir da problematização do ambiente escolar que experienciaram. Com isso, uma das possibilidades que o estágio apresenta é o trabalho de pesquisa e reflexão sobre os contextos educacionais vivenciados pelos estagiários. Pimenta \& Lima (2004, p 46), complementam dizendo que: 
A pesquisa no estágio como método de formação de futuros professores, se traduz, de um lado, na mobilização de pesquisas que permitam a ampliação e análise dos contextos onde os estágios se realizam; por outro, e em especial, se traduz na possibilidade de os estagiários desenvolverem postura e habilidades de pesquisador a partir das situações de estágio, elaborando projetos que thes permitam ao mesmo tempo compreender $e$ problematizar as situações que observam" (PIMENTA \& LIMA 2004, p 46).

Diante disso, foram realizadas diversas atividades relacionadas a essa perspectiva, dentre elas, estudos de textos relacionados à Educação Ambiental Crítica seguidos de discussões entre os alunos e a professora responsável,

Neste sentido foi possível a propiciar reflexões coletivas e individuais mais críticas sobre a relação dos seres humanos na e com a natureza, inseridos no sistema capitalista.

Posteriormente a essas discussões, foi proposto aos alunos que assistissem ao filme " $O$ menino e o mundo" e escrevessem sobre a relação encontrada por eles entre o filme e a Educação Ambiental Crítica, estudada no decorrer do curso.

\title{
3. METODOLOGIA
}

Para analisar os textos finais produzidos pelos alunos, foi utilizada a Pesquisa Qualitativa, que segundo Tozoni-Reis:

\begin{abstract}
A pesquisa qualitativa defende a ideia de que, na produção de conhecimentos sobre os fenômenos humanos e sociais, interessa muito mais compreender e interpretar seus conteúdos que descrevêlos" (TOZONI-REIS, 2007, p 10).
\end{abstract}

Foram feitas análises dos textos dos 13 alunos da turma e, posteriormente, foi feita categorização das falas, como proposto por Minayo e colaboradores (2016, p 316). A mesma tem por objetivo identificar falas que tem um mesmo sentido de comunicação, cuja frequência demonstre relevâncias para o objetivo analisado. Para a autora, a análise é realizada em três etapas, sendo a primeira a Pré-análise, em que é realizada uma leitura, seguida da exploração do material que consiste a segunda etapa, em que são feitos recortes e a organização dos dados, que são discutidos na terceira e última etapa, chamada de Tratamento de resultados.

\section{RESULTADOS E DISCUSSÃO}

A partir das análises das respostas dos alunos foram elaboradas quatro categorias. Abaixo segue o quadro: 


\section{Quadro 1: Categorias}

\begin{tabular}{|l|l|l|l|}
\hline Categorias & Descrição & Frequência & Ocorrência \\
\hline $\begin{array}{l}\text { Submissão dos trabalhadores } \\
\text { a situações precárias de } \\
\text { trabalho }\end{array}$ & $\begin{array}{l}\text { Nesta categoria é destacado como os } \\
\text { trabalhadores precisam se submeter a } \\
\text { condições precárias de trabalhos para } \\
\text { conseguir manter seu sustento. }\end{array}$ & $\begin{array}{l}\text { A1, A2, A3, A4, A5, } \\
\text { A7, A9, A10, A11 }\end{array}$ \\
\hline $\begin{array}{l}\text { Relação das questões sociais, } \\
\text { políticas e econômicas no } \\
\text { ambiente. }\end{array}$ & $\begin{array}{l}\text { Aqui se concentram as falas que } \\
\text { destacam como o ambiente é formado e } \\
\text { influenciado pela junção de aspectos } \\
\text { sociais, políticos, econômicos e culturais. }\end{array}$ & $\begin{array}{l}\text { A1, A3, A4, A5, A6, } \\
\text { A7, A8, A11 }\end{array}$ \\
\hline $\begin{array}{l}\text { Substituição do homem pela } \\
\text { máquina }\end{array}$ & $\begin{array}{l}\text { Nesta categoria se reúnem as falas que } \\
\text { mostram como a globalização e a } \\
\text { tecnologia contribuíram para que com o } \\
\text { passar dos anos o trabalho manual fosse } \\
\text { substituído pelas máquinas a fim de } \\
\text { conseguir atender as expectativas de } \\
\text { lucro no menor tempo possível }\end{array}$ & A2, A3, A4, A6, A8, \\
\hline Papel da mídia & $\begin{array}{l}\text { Os veículos midiáticos possuem uma } \\
\text { grande influência na sociedade, tendo } \\
\text { uma grande intervenção na maneira } \\
\text { como as pessoas recebem e interpretam } \\
\text { as informações. }\end{array}$ & A9 & A3, A4, A11 \\
\hline
\end{tabular}

Fonte: AUTORES, 2018.

Na primeira categoria foram agrupadas as falas em que os alunos se referiam à maneira como os trabalhadores são submetidos a trabalhos desumanos para poderem garantir seu próprio sustento. Um dos alunos trouxe como exemplo a cena em que ao final do expediente de trabalho todos os operários se enfileiraram e o chefe da plantação passa conferindo a condição física de cada funcionário, e aquele que não se encontrava em boas condições de saúde era demitido sem nenhum tipo de aviso prévio ou de apoio da empresa em que trabalhava, sem preocupação alguma com quais problemas isso acarretaria para ele.

Sabe-se que ao contrário dos outros animais que se moldam para adaptar-se a natureza, o homem realiza esse processo de maneira inversa, adaptando a natureza a seu favor. Essa prática o difere dos demais animais do ambiente e é descrita como a capacidade de realizar trabalho (SAVIANI, 2011).

Contudo, apesar do trabalho possibilitar ao homem uma autonomia, já que ele é capaz de modificar a natureza a seu favor, e também uma diferença em relação aos demais animais que não tem essa capacidade (SAVIANI, 2011), no sistema capitalista esse processo acontece de maneira diferente, pois a prática do trabalho o acorrenta e o torna cada vez mais preso ao sistema com condições precárias de trabalho, que movem o sistema. Situações semelhantes às citadas no filme podem ser encontradas de maneira massiva na sociedade, no ambiente educacional, inclusive com os professores.

O trabalho realizado pelo professor apresenta diversas características precárias, por exemplo, as jornadas de trabalho excessivas, o fato de receberem apenas pelos momentos em que estão em sala de aula e não receberem pelo tempo que gastam no planejamento de aulas, assim como o tempo de atividades extraclasse que são negligenciados.

Além disso, há casos em que os professores não têm estabilidade em seu emprego, não sendo possível assim, criar um vínculo duradouro com seu ambiente de trabalho. Ressaltando 
também o sucateamento das escolas, assim como uma baixa remuneração dos professores em vista de todo o esforço necessário para realização do seu trabalho (GASPARINI, 2005).

Essas precarizações nas atividades dos professores são, também, reflexos do intenso crescimento populacional do século XX, mais especificamente da década de 1930 até a década de 1980 que fez com que houvesse uma alta no número de vagas da profissão, mas que acabou acarretando na desvalorização da formação inicial dos professores, pois as demandas eram grandes e as exigências para atuação baixas (NAVARRO et al., 2006).

Diante disso, apesar da educação ser um processo que se caracteriza como um trabalho nãomaterial exclusivo dos seres humanos, essas características que contribuem para a precarização do trabalho docente, são determinadas pelo sistema capitalista de exploração vigente, que se preocupa com o aumento da produtividade e por consequência, extingue postos de trabalho, na super exploração do trabalho e no reforço do individualismo (KUENZER, 1998).

As falas abaixo trazem elementos significativos sobre a submissão dos trabalhadores a situações precárias de trabalho.

A10: "A falta de dignidade em relação ao ser humano é bem nítida quando vemos as condições deploráveis no trabalho, onde podemos relacionar muito bem com o trabalho escravo e o campo de concentração."

A11: "A desvalorização do trabalhador e os modos de produção agrícola vigentes naquela região também chamam atenção, uma vez que vemos muitos trabalhadores em uma monocultura de algodão submissos ao patrão. Pois necessitam daquela fonte de renda para ajudar na sobrevivência, algo que encontramos refletido diariamente no sistema capitalista."

Na segunda categoria os alunos apontaram como as questões sociais, políticas, econômicas e culturais interagem entre si influenciando os acontecimentos que ocorrem no meio ambiente. Reigota (2001) afirma que o meio ambiente pode ser definido como um lugar onde questões sociais e naturais se relacionam influenciando e determinando processos históricos, culturais, tecnológicos, etc. Por muito tempo o ambiente foi pensando e discutido sob um caráter naturalista, em que questões sociais não são pensadas nem discutidas, apenas questões ligadas à preservação e sustentabilidade (ADAMS, 2005), nesta perspectiva não era possível compreender o ambiente como uma junção destes aspectos nem compreender a influência de processos históricos na atual conjuntura da sociedade.

A compreensão do meio ambiente como consequência da dialética entre a natureza e o homem contribui para entender as constantes mudanças que ocorrem nele (REIGOTA, 1991), além de contribuir para a emancipação do indivíduo por meio da compreensão da realidade como um todo (LOUREIRO, TOZONI-REIS, 2007). Neste sentido, Leff (2001, p. 224) ainda complementa dizendo que:

O ambiente não é, pois, o meio que circunda as espécies $e$ as populações biológicas, é uma categoria sociológica (e não biológica), relativa a uma racionalidade social, configurada por 
comportamentos, valores e saberes, como também novo potencial produtivo (LEFF, 2001, p. 224).

Abaixo trazemos algumas falas que vão de encontro ao que foi discutido nessa categoria.

A11: "Como o modo que menino interage com o meio onde ele vive, vemos interações diretas com a natureza com os meios de produção agrícola e com a cultura daquele meio. Ressaltando a idéia de que o ambiente é uma construção histórica do homem, construção esta que é realizada por meio das interações e contradições do ser com o meio em que está inserido."

A8: "O filme "O menino e o mundo" (2014) dialoga com a educação ambiental crítica, pois trata diretamente da relação do homem com seu ambiente e sociedade e como essas relações definem o meio onde vive. Percebemos no filme como o sistema capitalista é vorás e engole tudo o que o cerca, vendo a tudo e a todos como um recurso, um meio para um fim específico, a saber, o lucro."

$\mathrm{Na}$ terceira categoria foi citado pelos alunos como a maneira que os avanços tecnológicos e a globalização do mundo influenciaram para que a mão de obra fosse deixada de lado cada vez mais em busca da maior obtenção de lucro em menor espaço de tempo. Assim, a substituição dos operários por máquinas contribuiu para que esse objetivo fosse alcançado.

O homem, desde os primórdios, sempre buscou maneiras de melhorar e aperfeiçoar suas habilidades, e após a Revolução Industrial com a intensa integração das máquinas, esse processo passou a buscar além de melhorias na escala do trabalho, a substituição direta do trabalho do homem. Como efeito, a máquina passa a ser item principal do processo de produção, o que implicou na desvalorização das habilidades manuais do artesão e dos operários, e no rompimento das relações sociais das etapas de produção (LONGO, 1989). Abaixo seguem as falas que demonstram alguns dos elementos utilizados para agrupar a terceira categoria.

A2: "(...) Também retrata a questão da substituição do trabalhador por máquinas e como isso afetou a disponibilidade de empregos."

A6: "(...) O menino seguiria os mesmos passos de seu pai. Saiu do sertão, para trabalhar em uma grande metrópole. Foi substituído por mão de obra automatizada e teve de trabalhar nos campos de colheita, antes de retornar à sua cidade natal (...)"

A quarta categoria representa as falas que mostram a influência da mídia na sociedade. Santo Diniz (2012) afirma que os veículos midiáticos possuem grande influência na sociedade, especialmente quando se dirigem aos jovens, uma vez que a mídia pode se manifestar de diversas formas, auxiliando no modo como as pessoas podem receber e interpretar as informações. Assim, segundo Belloni (1991, p.41) "a mídia representa um campo autônomo do 
conhecimento que deve ser estudado e ensinado às crianças da mesma forma que estudamos e ensinamos a literatura, por exemplo."

No entanto é importante ser cauteloso no trabalho com esta questão, já que McLuhan (1968) aponta que as informações geradas pelos veículos midiáticos, são agentes "produtores de acontecimentos", e não agentes "produtores de consciência". Caldas (2006) complementa dizendo que é preciso compreender a mídia além da aparência, tendo uma leitura crítica da mesma e não a considerando como uma verdade absoluta, mas como uma vertente da realidade. $O$ papel da mídia e a sua influência na sociedade são destacados em algumas falas abaixo.

A3: "É feito uma crítica à mídia, à quantidade de propaganda (que também pode ser visto nos outdoors na cidade), às informações desconexas com a realidade ou que não trazem o foco que precisa ser dado, desviando a atenção para coisas menos importantes."

A4: "Além de mostrar a alienação, consequência dessa relação empregado-patrão característica do modelo capitalista de produção, traz a questão da manipulação por meio da mídia, que mascara o vazio que as pessoas carregam estimulando o consumo como fator de felicidade."

\section{CONSIDERAÇÕES FINAIS}

Utilizando-se de análise de conteúdo e agrupando os relatos dos alunos em categorias pôde-se perceber que os mesmos conseguiram trazer elementos que indicaram as suas compreensões sobre o que vem a ser a Educação Ambiental Crítica e, com isso, a importância da compreensão dela para formação inicial de professores. $\mathrm{O}$ ambiente foi analisado pelos alunos como um todo e não apenas no seu sentido biológico, levando em conta os aspectos sociais, políticos, econômicos, culturais, entre outros.

Também foi possível notar como a utilização do cinema auxilia os alunos na compreensão dos assuntos propostos.

Considerando que, como futuros educadores é importante aproveitar estes momentos que o Estágio Supervisionado proporciona para se apropriar de aspectos relevantes para formação inicial de professores que sejam críticos, reflexivos e que busquem transformar a realidade em que se encontram.

\section{REFERÊNCIAS}

BELLONI, M. L. Educação para a mídia: missão urgente da escola. Comunicação \& Sociedade, São Bernardo do Campo, v. 10, n. 17, p. 36-46, ago. 1991.

CABRERA, J. O cinema pensa: uma introdução à filosofia através dos filmes. Rio de Janeiro: Rocco, 2006. 
GASPARINI, S. M.; BARRETO, S. M.; ASSUNÇÃO, A. Á. O professor, as condições de trabalho e os efeitos sobre sua saúde. Educação e Pesquisa, v. 31, n. 2, 2005.

HOLANDA, F. H.; FRERES, H.; GONÇALVES, L.e P. A Pedagogia das Competências e a Formação de Professores: Breve Consideração Critica. Eletrônica Arma da Crítica, Ano 1, Número 1 Janeiro, 28 ed. Petrópolis: Vozes, 2009.

KUENZER, A. Z.. As mudanças no mundo do trabalho e a educação: novos desafios para a gestão. Gestão democrática da educação: atuais tendências, novos desafios. São Paulo: Cortez, p. 33-57, 1998.

LONGO, W. P.. Ciência e Tecnologia: evolução, inter-relação e perspectivas. Anais do 9o Encontro Nacional de Engenharia de Produção, v. 1, p. 42, 1989

MCLUHAN, M. Revolução na comunicação. Rio de Janeiro: Zahar Editores, 1968. Os meios de comunicação como extensões do homem. São Paulo: Cultrix, 1969.

TOZONI-REIS, M. F. de C.. Metodologia de Pesquisa Científica. - Curitiba: IESDE Brasil S.A, 2007.

MINAYO, M. C S. O desafio do conhecimento. Pesquisa qualitativa em saúde. 2008.

PIMENTA, S. G. O estágio na formação de professores: Unidade teoria e prática? 4. ed. São Paulo: Cortez, 2001.

REIGOTA, M. O que é Educação Ambiental? 2. ed. São Paulo: Brasiliense, 2009.

SAVIANI, D. Sobre a natureza e especificidade da educação. Em Aberto, v. 3, n. 22, 2011.

APOIO: CAPES E FAPEMIG 